\title{
Remarkable spatial memory in a migratory cardinalfish.
}

\section{AUTHOR(S):}

Fukumori, Kayoko; Okuda, Noboru; Yamaoka, Kosaku; Yanagisawa, Yasunobu

\section{CITATION:}

Fukumori, Kayoko ...[et al]. Remarkable spatial memory in a migratory cardinalfish.. Animal cognition 2010, 13(2): 385-389

ISSUE DATE:

2010-03

URL:

http://hdl.handle.net/2433/128950

\section{RIGHT:}

The original publication is available at www.springerlink.com; This is not the published version. Please cite only the published version.; この 論文は出版社版でありません。引用の際には出版社版をご確認ご利用 ください。 


\section{Remarkable spatial memory in a migratory cardinalfish}

2

3 Kayoko Fukumori ${ }^{1}$, Noboru Okuda ${ }^{1}$, Kosaku Yamaoka $^{2}$ and Yasunobu Yanagisawa ${ }^{3}$

4

5 Affiliation:

$6{ }^{1}$ Center for Ecological Research, Kyoto University, 509-3, 2-chome, Hirano, Otsu,

7 Shiga 520-2113, Japan ${ }^{2}$ Graduate School of Kuroshio Science, Kochi University,

8200 Mononobe, Nangoku 783-8502, Japan $\quad{ }^{3}$ Faculty of Science, Ehime University,

9 2-5 Bunkyo-cho, Matsuyama 790-8577, Japan

10

$11 *$ *Corresponding author: Kayoko Fukumori

12 Center for Ecological Research, Kyoto University, 509-3, 2-chome, Hirano, Otsu, Shiga

13 520-2113, Japan

14 E-mail: fuku@ecology.kyoto-u.ac.jp

15 Phone: +81-77-5498215 Fax: +81-77-5498201

16

17 Keywords: spatial memory, migration, homing behaviour, breeding territory, orientation

18 cue

19

20

Short title: Spatial memory of cardinalfish 
23 The ability to orient and navigate within a certain environment is essential for all

24 animals, and spatial memory enables animals to remember the locations of such markers

25 as predators, home, and food. Here we report that the migratory marine cardinalfish

26 Apogon notatus has the potential to retain long-term spatial memory comparable to that

27 of other animals. Female A. notatus establish a small territory on a shallow boulder

28 bottom to pair and spawn with males. We carried out field research in two consecutive

29 breeding seasons on territory settlement by individually marked females. Females

30 maintained a territory at the same site throughout one breeding season. After

31 overwintering in deep water, many of them $(82.1 \%)$ returned to their breeding ground

32 next spring and most occupied the same site as in the previous season, with only a 0.56

$33 \mathrm{~m}$ shift on average. Our results suggest that female A. notatus have long-distance

34 homing ability to pinpoint the exact location of their previous territory, and retain spatial

35 memory for as long as 6 months. 
Spatial learning and memory are essential properties for animals to forage,

reproduce, avoid predators, and migrate. Studies suggest that fish are capable of spatial

learning and can use information in various different environments (Odling-Smee et al.

2006). In fish, spatial memory can enhance foraging rate (Hughes and Blight 1999),

territory defense (Lamanna and Eason 2003), and predator avoidance (Markel 1994). In

mammals and birds, the hippocampus plays a crucial role in spatial memory (Healy et al.

2005). Fish also possess a brain structure (telencephalon) that is functionally equivalent

to the hippocampus (Salas et al. 1996). Some fish species have the ability to integrate

geometric and non-geometric information to orient themselves (redtail splitfin Xenotoca

eiseni: Sovrano et al. 2002, 2005, 2007; Sovrano and Bisazza 2003; goldfish Carassius

auratus: Vargas et al. 2004; see reviews by Chiandetti and Vallortigara 2008).

It has been reported that fish use a variety of cues for orientation and navigation.

For example, coho salmon (Oncorhynchus kisutch), using an olfactory cue, can return to their natal stream 18 months after migration to sea (Cooper and Hasler 1974). Nishi and Kawamura (2005) suggested that the Japanese eel Anguilla japonica could use geomagnetic field as their directional guide for long-distance migration. Sticklebacks can associate visual cues with the status of potential food sources and use memorized information to guide foraging behaviour (Hughes and Blight 2000). Furthermore, juvenile Atlantic salmon (parr), Salmo salar, can use a coloured visual landmark as a local cue (Braithwaite et al. 1996) and goldfish, Carassius auratus, can learn a simple visual discrimination (landmark versus no landmark) to find a hidden food reward efficiently (Warburton 1990). 
Apogon notatus (Pisces: Apogonidae) is a marine gregarious cardinalfish

inhabiting the coastal waters of the northwestern Pacific. Female A. notatus start

establishing their territories on a boulder bottom more than two months prior to the breeding season, and maintain their territories throughout the breeding season (Okuda 1999) (see Figure 1). Females invite males shoaling above the boulder bottom to their territories to live in pairs for several weeks to months until spawning. After receiving a spawned egg mass in their buccal cavities, males leave the territories to mouthbrood in shoals. Female territorial behaviour is directed nearly exclusively toward potential egg predators (shoaling conspecifics) rather than toward mating competitors (Fukumori et al. 2009), suggesting that the primary function of the female territory is to avoid predation of the egg mass at the moment of spawning. After having several breeding cycles with different males, females abandon their territories in autumn to join large shoals in the water column (Okuda 1999). Thereafter, both males and females migrate to deep water to spend a couple of winter months there (Fukumori et al. 2008).

In the present study, we examined the homing ability of female A. notatus from their deep-water habitat to their neritic breeding habitat, by focusing on the positional shifts of territories occupied in two consecutive breeding seasons.

\section{Methods}

We conducted a field survey at Morode Beach, Shikoku Island, Japan, with the aid of SCUBA. We set a quadrat measuring $10 \times 20 \mathrm{~m}$ on the boulder area at a depth of 3.6-8.5 m and censused A. notatus there four or five times per month from April 2000 to 
March 2001 (but only once in June 2000). In each census, we counted the number of $A$. notatus, discriminating between territorial females and other fishes based on their positions and behaviour.

9

To assess how accurately females return to their territories over consecutive breeding seasons, we conducted a follow-up survey of individually marked females from 1999 to 2000. At the beginning of the breeding season in 1999, we caught 139 females in and around the quadrat using seine and hand nets, and marked them with visible implant elastomer (VIE) tags (see Okuda 1999 for details and ethical notes). After marking, we released them at their capture sites.

We plotted the locations of marked territorial females on the quadrat map in 15 weekly censuses conducted from June to October, 1999. To estimate territory size, we measured the area of a minimum convex polygon covering all locations plotted for each female whose locations were plotted at least three times. We also converted these locations into $\mathrm{x}$ and $\mathrm{y}$ coordinates and averaged the values of each coordinate to determine the centroid of the territory. In the following breeding season, we conducted 21 censuses for marked females found in the quadrat to detemine the centroid of each territory again. We used the distance between the two centroids as an index of their homing accuracy.

.

8

Breeding behaviour 
111 Female A. notatus started to establish their territories in March, and the number of 112 territorial females increased until May when the earliest spawning was observed (Figure

113 2). Thereafter, the number of territorial females was relatively constant until August but

114 declined drastically in September, the final month of the breeding season. After the last 115 spawning, females abandoned their territories to join shoals consisting of both sexes in

116 the water column. Shoals were near the breeding ground from September to November.

117 However, in December when the water temperature drastically decreased (Fukumori et 118 al. 2008), most of $A$. notatus disappeared from the breeding ground (Figure 2).

Homing Behaviour

Of 139 marked females, 118 established territories and their locations were repeatedly plotted on the quadrat map during the 1999 breeding season. Their breeding territories were $0.27 \pm 0.38 \mathrm{SE} \mathrm{m}^{2}(\mathrm{~N}=118)$. Of 117 marked females found at the last census of 1999, $75(64.1 \%)$ were found again in and around the same quadrat in the following breeding season. Most of them $(82.1 \%)$ occupied the same site as in the previous season, with only a $0.57 \pm 0.06 \mathrm{SE}$ m shift (Figure 3 ). This means that most fish returned to $20-30 \mathrm{~cm}$ of their previous breeding territory. The longest shift observed was $3.0 \mathrm{~m}$.

\section{Discussion} studies have suggested that memory capacity is determined by particular ecological conditions and life history demands (Mackney and Hughes 1995; Clayton 1998; Healy 
et al. 2005; Odling-Smee et al. 2006). Grey squirrels can remember the precise location of their food storage using a visual cue, and their spatial memory lasts for 62 days at most (Macdonald 1997). The nutcrackers are able to accurately relocate the caches they had made using visual cues and memory persists for 9-11 months (Balda and Kamil 1998; Gibson and Kamil 2009). In fish, spatial memory duration usually ranges from 8 to 330 days (Aronson 1971; Milinski 1994; Brown 2001). Lindauer (1963) reported that bees remember the color of a feeding place over several months. Furthermore, several species of wood ants (genus Formica) have been shown to exhibit high degrees of site or route fidelity based mainly on visual memories of environmental landmarks (Rosengren 1971; Rosengren and Fortelius 1986).

Homing behaviour has been observed in some cardinalfishes. The Banggai cardinalfish, Pterapogon kauderni, have the ability to home $40 \mathrm{~m}$ away from the original location of their group within $24 \mathrm{~h}$ of experimental translocation (Kolm et al. 2005). In three Australian cardinalfishes, Apogon doederleini, Cheilodipterus artus, and Cheilodipterus quinquelineatus, adult fish were able to return to their reefs within 3 days after being experimentally moved $2 \mathrm{~km}$ away (Marnane 2000). An isotopic study revealed that $A$. notatus overwinter in a deep-water habitat more than $600 \mathrm{~m}$ away from their breeding ground (Fukumori et al. 2008). This means that $A$. notatus also have long-distance homing ability.

Fish use several cues for orientation during migration: e.g., olfactory cue (coho salmon O. kisutch: Nevitt et al. 1994; five-lined cardinalfish C. quinquelineatus: Døving et al. 2006), the earth's magnetic field (blue shark Prionace glauca; stingray Urolophus halleri: Kalmijn 2000), and polarized light stimulus (juvenile rainbow trout 
161 Oncorhynchus mykiss: Parkyn et al. 2003). A magnetic cue is useful for long-distance

162

cruising during ocean migration, while olfactory and visual cues provide migrators spatial information on local environments. It is well known that salmonids use the earth's magnetic field as an orientation cue during ocean migration, while they also use olfactory and visual cues when approaching their natal stream and breeding ground (Atlantic salmon S. salar: Hansen et al. 1993). In the Australian cardinalfish, $C$. quinquelineatus, individuals can discriminate between conspecifics from their own reef and those from other reefs by scent, suggesting that their homing behaviour is based on an olfactory cue (Døving et al. 2006). Fukumori et al. (2009) indicated that female $A$. notatus establish their territories on the basis of the physical characteristics of the breeding ground, such as boulder size and structural complexity. Female A. notatus seem to use visual cues for pinpoint homing, based on the memory of detailed spatial structure around their territories, although they may use magnetic and/or olfactory cues to navigate in open water.

Recently, it has been reported that the medial and lateral pallia of teleost fish have functions analogous to the hippocampal pallium and pallial amygdala of mammals (Broglio et al. 2005). Some fish may have the potential to retain long-term spatial memory, as suggested in the present study.

In conclusion, in A. notatus, the period during which females are away from their territories is approximately 6 months: 3 months of shoaling after territory abandonment and 3 months in deep-water habitat in winter. Such long-term spatial memory is high among hitherto reported fish. In addition, females possess the ability to pinpoint the exact location of their previous territory. Future work will address the mechanistic basis 
for this kind of spatial memory.

\section{Acknowledgements}

We are grateful to Sosuke Oguri for providing a photograph of A. notatus habitat.

This study was financially supported by a Grant for Biodiversity Research of the 21st

Century COE (A14).

Aronson LR (1971) Further studies on orientation and jumping behavior in the gobbied fish, Bathygobius soporator. Ann N Y Acad Sci 188:378-392. doi:10.1111/j.1749-6632.1971.tb13110.x

Balda RP, Kamil AC (1998) The ecology and evolution of spatial of spatial memory in corvids of the southwestern USA: the perplexing pinyon jay. In: Balda RP, Pepperberg, IM, Kamil AC. (Eds.), Animal Cognition in Nature. Academic Press, London, UK, pp. 29-64

Braithwaite VA, Armstrong JD, McAdam HM, Huntingford FA (1996) Can juvenile Atlantic salmon use multiple cue systems in spatial learning? Anim Behav 51:1409-1415. doi:10.1006/anbe.1996.0144

Broglio C, Gómez A, Durán E, Ocaña FM, Jiménez-Moya F, Rodríguez F, Salas C (2005) Hallmarks of a common forebrain vertebrate plan: Specialized pallial 
areas for spatial, temporal and emotional memory in actinopterygian fish. Brain Res Bull 57:499-503. doi:10.1016/j.brainresbull.2005.03.021

214 Brown C (2001) Familiarity with the test environment improves escape responses in the crimson spotted rainbowfish, Melanotaenia duboulayi. Anim Cogn 4:109-113. doi:10.1007/s100710100105

217

Chiandetti C, Vallortigara G (2008) Spatial reorientation in large and small enclosures: comparative and developmental perspectives. Cogn Process 9:229-238. doi:10.1007/s10339-008-0202-6

Clayton NS (1998) Memory and the hippocampus in food-storing birds: a comparative approach. Neuropharmacology 37:441-452. doi:10.1016/S0028-3908(98)00037-9

Cooper JC, Hasler AD (1974) Electroencephalographic evidence for retention of olfactory cues in homing coho salmon. Science 25:336-338. doi:10.1126/science.183.4122.336 isotopes reveal life history polymorphism in the coastal fish, Apogon notatus. 
Fukumori K, Okuda N, Yanagisawa Y (2009) Female territoriality in a paternal mouthbrooding cardinalfish to avoid predation against spawned eggs. Can J Zool 87:508-514. doi: 10.1139-Z09-037

Gibson B, Kamil A (2009) The synthetic approach to the study of spatial memory: Have we properly addressed Tinbergen's “four questions”? Behav Proc 80:278-287. doi:10.1016/j.beproc.2008.11.013

Hansen LP, Jonsson N, Jonsson B (1993) Oceanic migration in homing Atlantic salmon. Anim Behav 45:927-941. doi:10.1006/anbe.1993.1112

Healy SD, De Kort SR, Clayton NS (2005) The hippocampus, spatial memory and food hoarding: a puzzle revisited. Trends Ecol Evol 20:17-22. doi:10.1016/j.tree.2004.10.006

Hughes RN, Blight CM (1999) Algorithmic behaviour and spatial memory are used by two intertidal fish species to solve the radial maze. Anim Behav 58:601-613. doi:10.1006/anbe.1999.1193

Hughes RN, Blight CM (2000) Two intertidal fish species use visual association 
261 Kalmijn AJ (2000) Detection and processing of electromagnetic and near-eld acoustic signals in elasmobranch fishes. Phil Trans R Soc Lond B 355:1135-1141. doi: 10.1098/rstb.2000.0654

264

265

266

267

268

269

270

271

272

273

274

275

Kolm N, Hoffman EA, Olsson J, Berglund A, Jones AG (2005) Group stability and homing behavior but no kin group structures in a coral reef fish. Behav Ecol 16:521-527. doi:10.1093/beheco/ari022

Lamanna JR, Eason PK (2003) Effects of landmarks on territorial establishment. Anim Behav 65:471-478. doi:10.1006/anbe.2003.2095

Lindauer M (1963) Allgemeine Sinnesphysiologie. Orientierung im Raum. Fortschr Zool 16:58-140

Macdonald IMV (1997) Field experiments on duration and precision of grey and red squirrel spatial memory. Anim Behav 54:879-891. doi:10.1006/anbe.1996.0528

Mackney PA, Hughes RN (1995) Foraging behaviour and memory window in sticklebacks. Behaviour 132:1241-1253. doi:10.1163/156853995X00559

Markel RW (1994) An adaptive value of spatial learning and memory in the blackeye goby, Coryphopterus nicholsi. Anim Behav 47:1462-1464. doi:10.1006/anbe.1994.1194

Marnane MJ (2000) Site fidelity and homing behaviour in coral reef cardinalfishes. J 
Fish Biol 57:1590-1600. doi:10.1111/j.1095-8649.2000.tb02234.x

287

Milinski M (1994) Long-term memory for food patches and implications for ideal free distributions in sticklebacks. Ecology 75:1150-1156

290

Nevitt GA, Dittman AH, Quinn TP, Moody WJJ (1994) Evidence for a peripheral olfactory memory in imprinted salmon. Proc Natl Acad Sci USA 91:4288-4292

293 eel phase. J Fish Biol 67:1213-1224. doi:10.1111/j.1095-8649.2005.00817.x

296

297

298

299

Odling-Smee L, Simpson S, Braithwaite VA (2006) The role of learning in fish orientation. In: Brown C, Laland K, Krause J. (Eds.), Fish Cognition and Behavior. Blackwell Publishing, West Sussex, England, pp 119-138

300

Okuda N (1999) Sex roles are not always reversed when the potential reproductive rate is higher in females. Am Nat 153:540-548. doi:10.1086/303196 doi:10.1006/anbe.2003.2136

307

Rosengren, R. (1971) Route fidelity, visual memory and recruitment behaviour in Fenn 133:1-106. 
312 Rosengren R, Fortelius W (1986) Ortstreue in foraging ants of the Formica rufa group Hierarchy of orienting cues and long-term memory. Insect Soc 33:306-334.

Salas C, Broglio C, Rodríguez F, López JC, Portavella M, Torres B (1996) Telencephalic ablation in goldfish impairs performance in a 'spatial constancy' problem but not in a cued one. Behav Brain Res 79:193-200. doi:10.1016/0166-4328(96)00014-9

Sovrano VA, Bisazza A, Vallortigara G (2002) Modularity and spatial reorientation in a simple mind: encoding of geometric and non-geometric properties of a spatial environment by fish. Cognition 85:B51-B59. doi:10.1016/S0010-0277(02)00110-5

Sovrano VA, Bisazza A (2003) Modularity as a fish views it: conjoining geometric and nongeometric information for spatial reorientation. J Exp Psychol: Anim Behav Process 29:199-210. doi:10.1037/0097-7403.29.3.199

332

Sovrano VA, Bisazza A, Vallortigara G (2007) How fish do geometry in large and in small spaces. Anim Cogn 10:47-54. doi:10.1007/s10071-006-0029-4 
336 Vargas JP, Lopez JC, Salas C, Thinus-Blanc C (2004) Encoding of geometric and featural spatial information by goldfish (Carassius auratus). J Comp Psychol $118: 206-216$

339

340

\section{Figure legends}

Fig. 1 Shallow boulder habitat of A. notatus at Morode Beach, Japan. There are three pairs (black arrows) in the photograph (Photo by S. Oguri). See text for details.

Fig. 2 Monthly changes in the total number of A. notatus (grey bars) and the number of territorial females (closed circles) in the study quadrat. Black, horizontal hatched, and dotted bars indicate periods of female territory settlement, shoaling, and winter migration, respectively.

Fig. 3 Frequency distribution of distance (m) between centroids of territories settled by each marked female in two consecutive breeding seasons. 


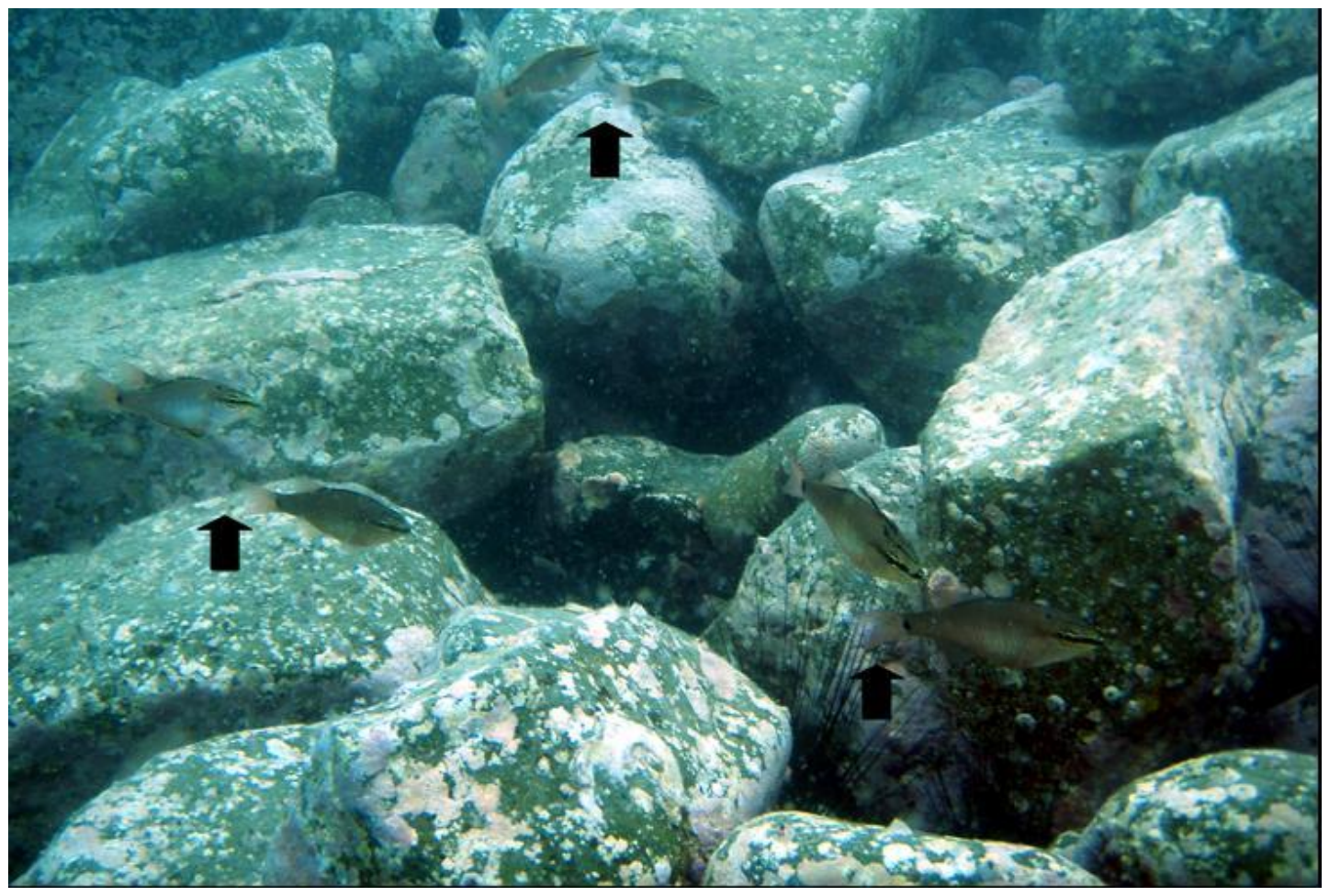

367

368

369

370

374 Fukumori K. et al. Fig. 1 


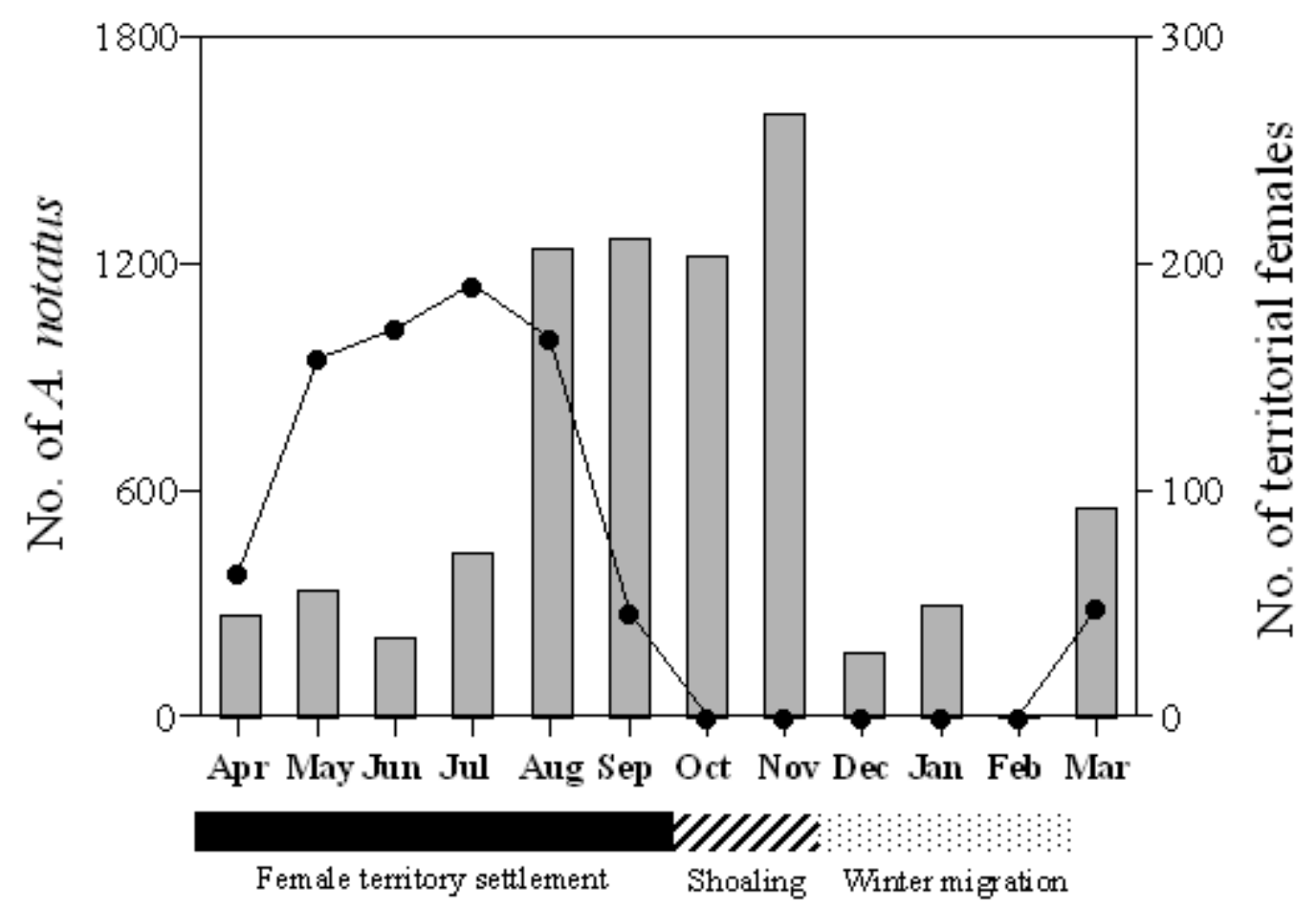

381

382

Fukumori K. et al. Fig. 2 
392

393

394

395

396

397

398

399

400

401

402

403

404

405

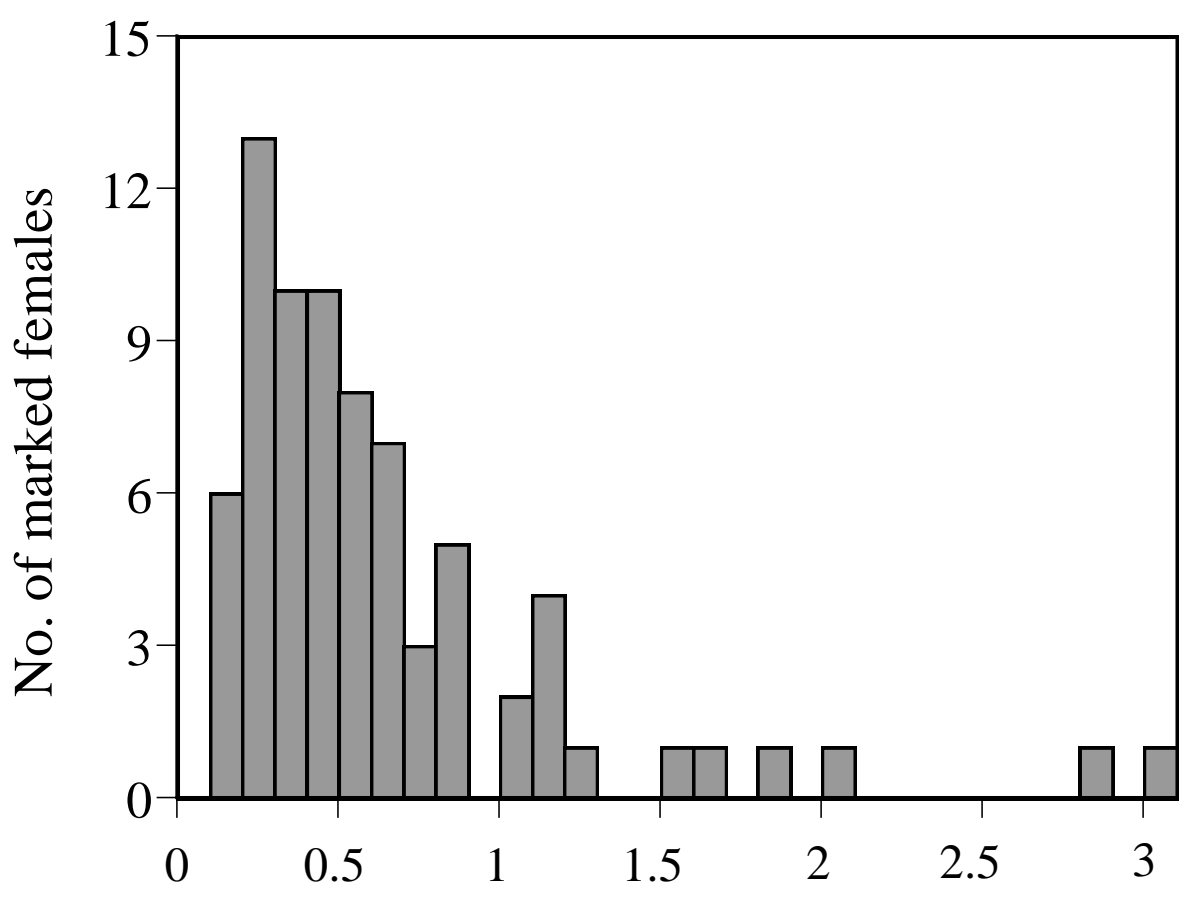

406

Distance between territory centroids

407

408

409

410

411

412

413

414 Fukumori K. et al. Fig. 3 